\title{
多軸工作機械の幾何学的誤差を含む加エシミュレーション のための工具掃引体導出に関する研究*
}

\author{
ーラジアスエンドミルにおけるエ具掃引領域形状の分類一 \\ 荒井 航**田中文基*** 小野里 雅彦***
}

Study on Generating Tool Swept Volumes for Machining Simulation with Geometric Errors of Multi-Axis Machine Tools - Classification of Shapes of Tool Swept Area for Radius Endmill -

Wataru ARAI, Fumiki TANAKA and Masahiko ONOSATO

Error characteristics of multi-axis machine tools such as geometric errors cause machined errors on machined surfaces of machined parts. To estimate the machined errors on machined parts, shapes of machined parts with machined errors should be derived in computer simulation. By representing shapes of machined parts as difference set between a workpiece and tool swept volumes, the machined errors on machined surfaces can be estimated. A tool swept volume is composed of tool swept areas on tool surfaces that form surfaces of the tool swept volume. Tool swept areas on tool surfaces change its shape depending on tool motion. In order to derive tool swept volumes without any restriction on tool motion, all shape types of tool swept areas should be classified as tool swept types for general tools in multi-axis machining. Hence, in our previous study, tool swept types of cylindrical surface (side surface of a flat endmill), tapered surface (side surface of a taper endmill) and planar surface (bottom surface of an endmill) were classified. In this paper, tool swept types of torus that represents a corner radius of a radius endmill are classified into 8 tool swept types.

Key words: machine tool, tool swept volume, classification of shapes of tool swept area, geometric errors of machine tool, machining simulation, radius endmill, multi-axis machining

\section{1. 緒言}

多軸工作機械を用いた部品加工は, 駆動軸の位置決め誤差や 回転誤差, 加工プロセスに起因した熱・振動により生じる誤差等 の誤差特性による影響を受けるため, 工作物の品質が低下する 1). 多軸工作機械の誤差特性による部品加工への影響は, 加工形 状 2)に生じる加工誤差や, 工具中心等の軌跡 3)に生じる変化量に よって表現されている. このような多軸工作機械の誤差特性に よる影響下で高精度な加工物を得るには, 加工形状に生じる加 工誤差をシミュレーションによって予測し, 評価した結果に基 づき工程設計を行うことが望ましい2). 仕上げ加工等の工具の回 転速度が送り速度よりも十分速い加工を対象としたシミュレー ションでは, 回転体として近似表現された工具形状が用いられ る. このとき加工形状は, 工作物と, 近似された工具形状の移動 領域の総和を表す工具掃引体との, 差集合として表現される. 工 具掃引体は, 工具運動により新しく生成される工具掃引面と, 工 具パスの初期/終了位置における工具形状の境界面から構成さ れる. 工具表面上において工具掃引面を形作る領域を工具掃引 領域とすると, その形状は工具運動によって曲線や面となる. そ のため, 多軸加工にて一般的な工具形状について, 工具掃引領域 の形状と, それに対応する工具運動を明らかにし, 工具運動に制 約なく工具掃引体を導出可能と寸る必要がある. また, CAD の マクロ機能により, 工具パス上の離散的な位置に配置した工具

\footnotetext{
*原稿受付 平成 29 年 2 月 6 日

掲㦲決定 平成 29 年 5 月 31 日

** 学生会員 北海道大学大学院情報科学研究科（北海道札幌市北 区北 14 条西 9)

***正会員 北海道大学大学院情報科学研究科
}

形状の和集合として工具掃引体を表現する方法もあるが, 加工 面全体に対する評価を行う場合, 工具を非常に多くの位置に配 置する必要があるため, 適していない. そのため, 現在の主な工 具掃引体に関する研究では, 工具掃引領域において速度ベクト ルと法線ベクトルが直交するという条件に基づいた，工具掃引 領域を表す工具掃引条件式 4)や, 工具掃引領域の軌跡を表す Sweep-envelope differential equation(SEDE)5)が用いられてい る. Chiou ら ${ }^{6)}$ はテーパ形状とトーラス形状から構成される回 転体の工具, LiMin ら 》は不連続領域のない回転体, を対象に, 工具掃引条件式を用いた掃引体導出手法を提案した. また, Bharat ら 9)は, 不連続領域を持たない回転体を対象に, SEDE を用いた掃引体導出手法を提案した. しかし, これらの手法は, 工具軸と垂直に交わる軸回りの回転運動といった, 多軸加工で 一般的な工具運動における工具掃引体を導出することができな い. また, 回転工具の掃引体を導出可能な市販 $\mathrm{CAD}$ システムに おいても同様の問題がある. これに対し Seok ら 8)は, フラット エンドミル側面を表す円柱に対し, 工具掃引領域の形状と, それ に対応する工具運動を明らかにすることで, 工具運動に制約な く工具掃引体を導出可能とした. しかし, 多軸加工で一般的なテ ーパエンドミルやラジアスエンドミルは, 円柱だけでは表現で きない. そのため, 円錐形状(テーパエンドミル側面), トーラス 形状(ラジアスエンドミルのコーナーラジアス側面), 平面(ラジ アスエンドミルの工具底面)や工具表面の法線ベクトルが不連続 な領域, を対象に, 工具掃引領域の形状と, それに対応寸る工具 運動を明らかにする必要がある. 以上より本研究では, 工具の回 転速度が送り速度に対し十分速い加工において, 多軸加工にて 一般的な工具を対象に，工具掃引条件の成立条件を解析するこ 
とで工具掃引領域の形状と, それに対応する工具運動を工具掃 引タイプとして分類し, 工具動作に制限のない工具掃引体導出 手法を提案する. 先行研究では, 図 1 に示すように, 円柱は 3 種 類, 円錐は 9 種類, 平面は 3 種類の工具掃引タイプがあること を明らかにした 10)11)。本論文では, ラジアスエンドミルのコー ナーラジアス側面を表すトーラス形状の工具掃引タイプを分類 する.

\section{2. 工具掃引条件に基づく工具掃引体導出}

\section{1 工具掃引面導出のための工具掃引条件式}

工具の回転速度が送り速度よりも十分速い加工を対象とした シミュレーションでは, 回転体として近似表現された工具形状 が用いられる. このとき工具掃引体は, 図 2 に示すように, 工具 運動に伴い新しく生成される面である工具掃引面(Tool swept surface) と, 工具パスの初期・終了位置において工具掃引体の最 外面に属する工具の表面(Surface of tool)で構成される. 工具㛿 引面は, 工具パスの各位置における工具表面上の工具掃引領域 (Tool swept area)から構成され, 工具掃引領域の形状は工具運 動によって異なる. 図 2 は, 円柱とトーラスで構成される工具 を, 直進させながら, 直進方向一徐々に傾かせる場合を示してお り, 工具掃引領域の形状は, 円柱では 2 本の曲線, トーラスでは 下に凸の曲線となる. 本研究では, 工具表面上の工具掃引領域に 生じる速度ベクトル $\mathbf{v}$ と法線ベクトル $\mathbf{n}$ 金直に交わるという工 具掃引条件(tangency condition)から得られる工具掃引条件式 (1)を解くことで工具掃引領域を求め, 工具掃引面を導出する.

$$
\mathbf{n} \cdot \mathbf{v}=0
$$

これ以降, 工具掃引条件の成立条件を解析し, 工具掃引領域の 形状と, それに対応する工具運動を工具摛引タイプとして分類 する.

\section{2. コーナーラジアスの形状表現とエ具掃引条件式}

工具形状は, 工具座標系の ZX 平面で定義した母線を工具軸 回りに回転した回転体として表現される. 本論文では, ラジアス エンドミルの母線を, 図 3 に示すように, 上下のテーパを表す 線分と, コーナーラジアスを表す円弧で表現する.このとき，コ ーナーラジアスはトーラス形状となる. 工具座標系におけるコ ーナーラジアスの工具表面上の点への位置ベクトル $\mathbf{r}_{\mathrm{T}}$, 法線ベ クトル $\mathbf{n}_{\mathrm{T}}$ は，式(2), (3)となる. なお，Tは転置を表す.

$$
\mathbf{r}_{\mathrm{T}}(\phi, \rho)=\left[\begin{array}{c}
\left(\mathrm{E}+\mathrm{R}_{\mathrm{tc}} \cos \phi\right) \cos \rho \\
\left(\mathrm{E}+\mathrm{R}_{\mathrm{tc}} \cos \phi\right) \sin \rho \\
-\left(\mathrm{H}+\mathrm{R}_{\mathrm{tc}} \sin \phi\right)
\end{array}\right]
$$

$$
\mathbf{n}_{\mathrm{T}}(\phi, \rho)=\left[\begin{array}{lll}
\cos \phi \cos \rho & \cos \phi \sin \rho & -\sin \phi
\end{array}\right]^{\mathrm{T}}
$$

また, $\mathrm{R}_{\mathrm{tc}}$ は円弧の半径, Eは工具軸と円弧中心点の距雄, $\mathrm{H}$ は工 具座標系原点と円弧中心点の距離, $\rho(0 \leq \rho<2 \pi)$ は工具軸回り の角度を表す変数, $\phi$ は円弧中心点回りの角度を表す変数である. $\phi$ 範囲は, トーラス上側テーパの角度を $\phi_{\text {begin }}\left(\phi_{\text {begin }} \geq 0\right)$, 下 側テーパの角度を $\pi / 2-\phi_{\text {end }}\left(\phi_{\text {end }} \leq \pi / 2\right)$ とすると, $\phi_{\text {begin }} \leq$ $\phi \leq \phi_{\text {end }}$ となる. なお, 式(2), (3)は, $\phi=0$ のとき円柱の一部, $\phi=\pi / 2$ のとき工具底面の一部を表し, 先行研究 10) 11)にて分類 済みである.これ以降, $\phi_{\text {begin }}>0, \phi_{\text {end }}<\pi / 2$ とし, 工具掃引 タイプを分類する. ここで, 図 4 に示すように, 工具表面上の 点への位置ベクトル $\mathbf{r}_{\mathrm{T}}$ を, その点における法線ベクトル $\mathbf{n}_{\mathrm{T}}$ と工 具軸方向のベクトル $\mathbf{r}_{\mathbf{a}}$ を用い, 式(4)として定義する.

$$
\begin{aligned}
& \mathbf{r}_{\mathrm{T}}(\phi, \rho)=\mathbf{r}_{\mathrm{a}}(\phi)+m(\phi) \mathbf{n}_{\mathrm{T}}(\phi, \rho) \\
& =(-\mathrm{H}+\mathrm{E} \tan \phi)\left[\begin{array}{lll}
0 & 0 & 1
\end{array}\right]^{\mathrm{T}}+\left(\frac{\mathrm{E}}{\cos \phi}+\mathrm{R}_{\mathrm{tc}}\right) \mathbf{n}_{\mathrm{T}}(\phi, \rho)
\end{aligned}
$$

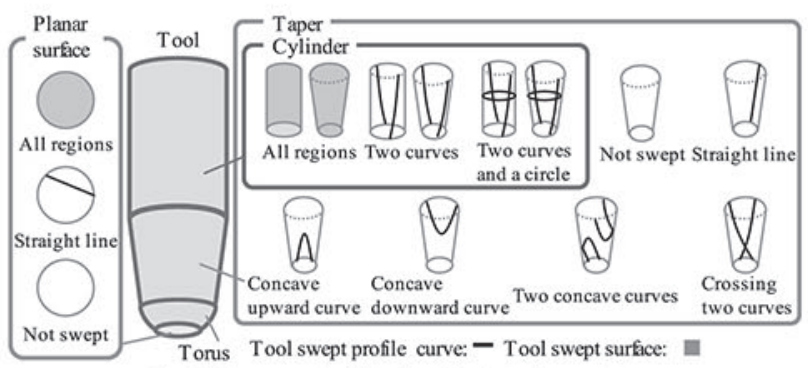

Fig. 1 Components of tool and their tool swept types

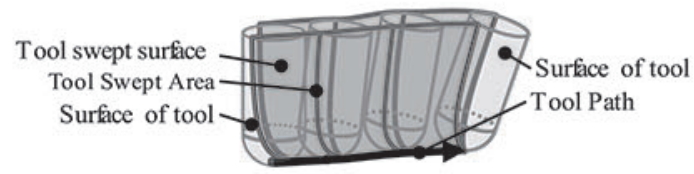

Fig. 2 Components of tool swept volume

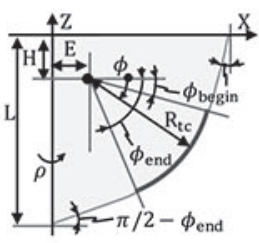

Fig. 3 Generating line of radius endmill

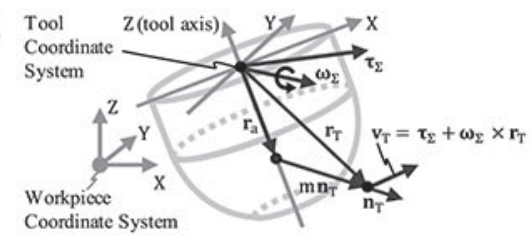

Fig. 4 Coordinate systems and vectors

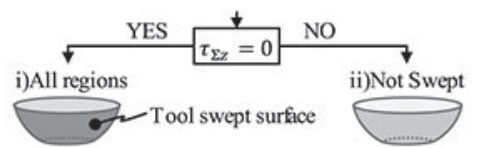

Fig. 5 Overview of classifying when $\forall \phi, \mathrm{A}(\phi) \equiv 0$ and $\mathrm{B}(\phi) \equiv 0$

ワールド座標系を工作物座標系, ローカル座標系を工具座標 系とする. 式(4)で表現される位置ベクトル $\mathbf{r}_{\mathrm{T}}$ の工具座標系にお ける速度ベクトル $\mathbf{v}_{\mathrm{T}}$ を, 図 4 に示すように, 工具座標系原点の 平行移動速度ベクトル $\boldsymbol{\tau}_{\Sigma}$, 工具座標系原点を通過する角速度べ クトル $\omega_{\Sigma}$ を用い, 式(5)として定義する.

$$
\begin{gathered}
\mathbf{v}_{\mathrm{T}}(\phi, \rho)=\boldsymbol{\tau}_{\Sigma}+\omega_{\Sigma} \times \mathbf{r}_{\mathrm{T}}(\phi, \rho) \\
\left\{\begin{array}{c}
\boldsymbol{\tau}_{\Sigma}=\left[\begin{array}{lll}
\tau_{\Sigma \mathrm{x}} & \tau_{\Sigma \mathrm{y}} & \tau_{\Sigma \mathrm{z}}
\end{array}\right]^{\mathrm{T}} \\
\boldsymbol{\omega}_{\Sigma}=\left[\begin{array}{lll}
\omega_{\Sigma \mathrm{x}} & \omega_{\Sigma \mathrm{y}} & \omega_{\Sigma \mathrm{z}}
\end{array}\right]^{\mathrm{T}}
\end{array}\right.
\end{gathered}
$$

式(1), (3), (4), (5)より, 工具揥引条件式(6)を得る.

$$
\begin{aligned}
\mathbf{n}_{\mathrm{T}}(\phi, \rho) \cdot \mathbf{v}_{\mathrm{T}}(\phi, \rho) \\
=\mathbf{n}_{\mathrm{T}}(\phi, \rho) \cdot\left(\boldsymbol{\tau}_{\Sigma}+\omega_{\Sigma} \times\left(\mathbf{r}_{\mathrm{a}}(\phi)+m(\phi) \mathbf{n}_{\mathrm{T}}(\phi, \rho)\right)\right) \\
=\mathbf{n}_{\mathrm{T}}(\phi, \rho) \cdot\left(\boldsymbol{\tau}_{\Sigma}+\omega_{\Sigma} \times \mathbf{r}_{\mathrm{a}}(\phi)\right) \\
=\mathrm{A}(\phi) \cos \rho+\mathrm{B}(\phi) \sin \rho-\tau_{\Sigma \mathrm{z}} \sin \phi=0 \\
\qquad \begin{array}{l}
\mathrm{A}(\phi)=\left(\tau_{\Sigma \mathrm{x}}-H \omega_{\Sigma \mathrm{y}}\right) \cos \phi+E \omega_{\Sigma \mathrm{y}} \sin \phi \\
\mathrm{B}(\phi)=\left(\tau_{\Sigma \mathrm{y}}+H \omega_{\Sigma \mathrm{x}}\right) \cos \phi-\mathrm{E} \omega_{\Sigma \mathrm{x}} \sin \phi
\end{array}
\end{aligned}
$$

これ以降, 式(6)の $\cos \rho, \sin \rho$ の係数 $\mathrm{A}(\phi), \mathrm{B}(\phi)$ )值に基づき, $\forall \phi に て \mathrm{~A}(\phi) \equiv 0, \mathrm{~B}(\phi) \equiv 0$ の場合, $\phi=\phi_{\text {zero }}$ にて $\mathrm{A}\left(\phi_{\text {zero }}\right)=0$, $\mathrm{B}\left(\phi_{\text {zero }}\right)=0$ の場合, $\mathrm{A}(\phi), \mathrm{B}(\phi)$ が同時に 0 とならない場合, の 3 つの状態にわけ, 工具掃引タイプを分類する.

\section{3.コーナーラジアスのエ具掃引タイプの分類}

3.1. $\forall \phi \mid$ に $\mathrm{A}(\phi) \equiv 0, \mathrm{~B}(\phi) \equiv 0$ である場合

平行移動速度ベクトル $\boldsymbol{\tau}_{\Sigma}$ と角速度ベクトル $\omega_{\Sigma}$ が式(7)を満た すとき, 式(6)において, $\forall \phi に て A(\phi) \equiv 0, \mathrm{~B}(\phi) \equiv 0$ となる.

$$
\tau_{\Sigma x}=0, \omega_{\Sigma y}=0, \tau_{\Sigma y}=0, \omega_{\Sigma x}=0
$$

このとき, 工具掃引条件式は式(8)となる.

$$
-\tau_{\Sigma z} \sin \phi=0
$$


ここで, $0<\phi<\pi / 2$ より $\sin \phi \neq 0$ であるため, 図 5 に示すよう に, 工具掃引タイプは $\tau_{\Sigma z}=0$ と $\tau_{\Sigma z} \neq 0$ の 2 通りになる. 従って, 式(7)を満たし $\tau_{\Sigma z}=0$ であるとき, 工具は工具軸回りに回転し, 工具掃引条件は $\phi, \rho$ に関わらず成立するため, コーナーラジアス 全体が掃引される. また, $\tau_{\Sigma z} \neq 0$ であるとき，工具は工具軸方 向に並進移動し, 工具掃引条件は $\phi, \rho$ に関わらず成立しないため, コーナーラジアスは掃引されない.

\section{2. $\phi=\phi_{\text {zero }}$ にて $\mathrm{A}\left(\phi_{\text {zero }}\right)=0, \mathrm{~B}\left(\phi_{\text {zero }}\right)=0$ である場合}

平行移動速度ベクトル $\tau_{\Sigma}$ と角速度ベクトル $\omega_{\Sigma}$ が, 式(7)を満た さず, $\mathrm{A}\left(\phi_{\text {zero }}\right)=0, \mathrm{~B}\left(\phi_{\text {zero }}\right)=0$ の連立方程式より得られる式 (9)を満たすとき, 式 $(10)$ を満たす $\phi_{\text {zero }}$ にて $\mathrm{A}\left(\phi_{\text {zero }}\right)=$ $\mathrm{B}\left(\phi_{\text {zero }}\right)=0$ となる.

$$
\begin{gathered}
\omega_{\Sigma x} \tau_{\Sigma x}+\omega_{\Sigma y} \tau_{\Sigma y}=0 \\
\tan \phi_{\text {zero }}=\frac{\tau_{\Sigma y}+H \omega_{\Sigma x}}{E \omega_{\Sigma x}},\left(=\frac{\tau_{\Sigma x}-H \omega_{\Sigma y}}{-E \omega_{\Sigma y}}\right)
\end{gathered}
$$

なお, $\omega_{\Sigma x}$ と $\omega_{\Sigma y}$ は同時に 0 にはならない. このとき $\phi=\phi_{\text {zero }}$ で は, 工具㛿引条件式が式(11)となる.

$$
-\tau_{\Sigma \mathrm{z}} \sin \phi=0
$$

$0<\phi<\pi / 2$ 範囲では $\sin \phi \neq 0$ であるため, 図 6 に示すよう に, $\tau_{\Sigma z}=0$ と $\tau_{\Sigma z} \neq 0$ の場合で工具掃引タイプが異なる.

式(7)を満たさず, 式(9)を満たし， $\tau_{\Sigma z}=0$ であるとき， $\phi=$ $\phi_{\text {zero }}$ では $\mathrm{A}\left(\phi_{\text {zero }}\right)=\mathrm{B}\left(\phi_{\text {zero }}\right)=0$ であるため, 工具掃引条件は 変数 $\rho$ に関係なく成立する. よって, $\phi=\phi_{\text {zero }}$ の工具断面を表す 円が工具掃引線となる. また, $\phi \neq \phi_{\text {zero }}$ では, $\cos \rho, \sin \rho$ を合 成した工具掃引条件式は式(12)となり, $\sin (\rho+\mu(\phi))=0$ とな り, $\mu(\phi)$ は一意に定まるため, $\rho$ の解は 2 つ存在する.

$$
\begin{aligned}
& \sqrt{A(\phi)^{2}+B(\phi)^{2}} \sin (\rho+\mu(\phi))=0 \\
& \mu(\phi)=\tan ^{-1} \frac{\sin \mu(\phi)}{\cos \mu(\phi)}=\tan ^{-1} \frac{A(\phi)}{B(\phi)}
\end{aligned}
$$

よって, $\phi \neq \phi_{\text {zero }}$ の工具断面上の 2 つの具掃引点を結んだ 2 本の曲線が工具掃引線となる. これより, $\phi_{\text {begin }}, \phi_{\text {end }}$ と $\phi_{\text {zero }}$ の 大小関係で, 図 7 に示す 2 種類の工具掃引タイプのいずれかと なる. i) $\phi_{\text {zero }}<\phi_{\text {begin }}$ または $\phi_{\text {end }}<\phi_{\text {zero }}$ である場合, 図 7 (a) に示すように, 2 本の曲線が工具掃引曲線となる. ii) $\phi_{\text {begin }} \leq$ $\phi_{\text {zero }} \leq \phi_{\text {end }}$ である場合, 図 7 (b)に示すように, 円と 2 本の曲 線が工具掃引線となる.

また, 式(7)を満たさず, 式(9)を満たし， $\tau_{\Sigma z} \neq 0$ であるとき, 工具掃引タイプ分類のため, 工具掃引条件式の $\cos \rho, \sin \rho$ を合 成し, 式(13)を得る.

$$
\begin{gathered}
\sqrt{A(\phi)^{2}+B(\phi)^{2}} \sin (\rho+\mu(\phi))-\tau_{\Sigma z} \sin \phi=0 \\
\mu(\phi)=\tan ^{-1} \frac{\sin \mu(\phi)}{\cos \mu(\phi)}=\tan ^{-1} \frac{A(\phi)}{B(\phi)}
\end{gathered}
$$

ここで, $0<\phi<\pi / 2$ の範囲では $\sin \phi \neq 0$ であるため, 工具掃引 条件式(13)の $\rho$ の解の数は, 付録に示すように, 式(14)の值より 判別できる.

$$
D_{\rho}(\phi)=A(\phi)^{2}+B(\phi)^{2}-\left\{\tau_{\Sigma z} \sin \phi\right\}^{2}
$$

式(14)を用いた工具掃引タイプの分類は 3.3.と同じ手順である ため, まとめて 3.3.にて説明する。

\section{3. $\mathrm{A}(\phi), \mathrm{B}(\phi)$ が同時に0 とならない場合}

3.1.また 3.2.とならない場合, 工具掃引条件式(6)における $\mathrm{A}(\phi), \mathrm{B}(\phi)$ は同時に 0 とならない. ここで, 工具掃引タイプを分 類するため, $\cos \rho, \sin \rho$ を合成し, 工具掃引条件式(15)を得る.

$$
\begin{gathered}
\sqrt{A(\phi)^{2}+B(\phi)^{2}} \sin (\rho+\mu(\phi))-\tau_{\Sigma z} \sin \phi=0 \\
\mu(\phi)=\tan ^{-1} \frac{\sin \mu(\phi)}{\cos \mu(\phi)}=\tan ^{-1} \frac{A(\phi)}{B(\phi)}
\end{gathered}
$$

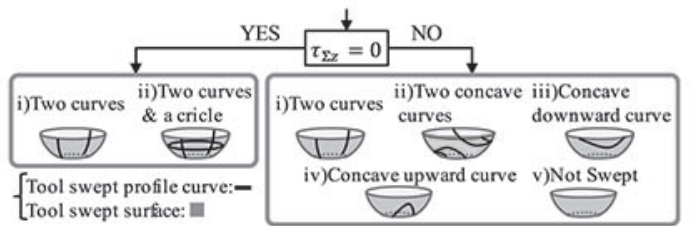

Fig. 6 Overview of classifying when $\phi=\phi_{\text {zero }}, \mathrm{A}\left(\phi_{\text {zero }}\right)=\mathrm{B}\left(\phi_{\text {zero }}\right)=0$

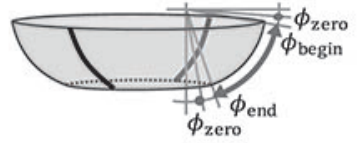

(a) Two curves

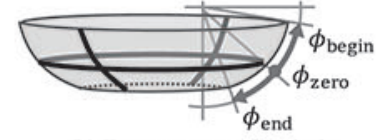

(b) Two curves and a circle - : Tool swept profile curve

Fig. 7 Tool swept types of torus in Section 3.2

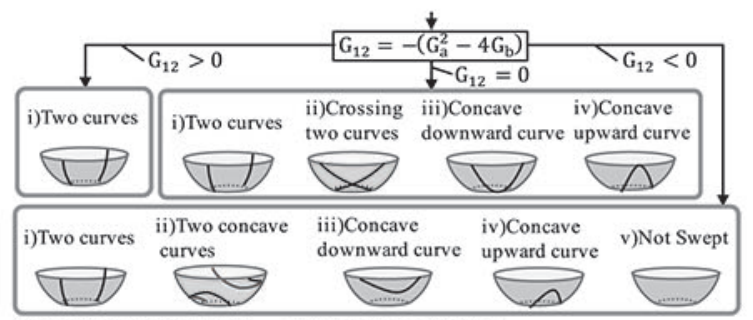

Tool swept profile curve: - Tool swept surface: $G_{a}=-2 E\left\{H\left(\omega_{\Sigma x}^{2}+\omega_{\Sigma y}^{2}\right)+\omega_{\Sigma x} \tau_{\Sigma y}-\omega_{\Sigma y} \tau_{\Sigma x}\right\}\left\{\left(H \omega_{\Sigma x}+\tau_{\Sigma y}\right)^{2}+\left(H \omega_{\Sigma y}-\tau_{\Sigma x}\right)^{2}\right\}^{-1}$ $G_{b}=\left\{E^{2}\left(\omega_{\Sigma x}^{2}+\omega_{\Sigma y}^{2}\right)-\tau_{\Sigma \Sigma}^{2}\right\}\left\{\left(H \omega_{\Sigma x}+\tau_{\Sigma y}\right)^{2}+\left(H \omega_{\Sigma y}-\tau_{\Sigma x}\right)^{2}\right\}^{-1}$

Fig. 8 Overview of classifying when $\mathrm{A}(\phi)=0$ and $\mathrm{B}(\phi)=0$ are not satisfied simultaneously

$0<\phi<\pi / 2$ 範囲では $\sin \phi \neq 0$ であるため, $\tau_{\Sigma z}=0$ と $\tau_{\Sigma z} \neq 0$ の場合で工具㛿引タイプが異なる。

$\tau_{\Sigma \mathrm{z}}=0$ のとき, 工具探引条件式(15)にて $\sin (\rho+\mu(\phi))=0$ と なり, $\mu(\phi)$ は一意に定まるため, $\rho$ の解は 2 つ存在する.よって, すべての工具断面上に 2 つの工具掃引点が存在し, それらの工 具掃引点を結んだ 2 本の曲線が工具掃引曲線となる.

$\tau_{\Sigma z} \neq 0$ であるとき, $0<\phi<\pi / 2$ 䇛囲では $\sin \phi \neq 0$ である ため, 工具掃引条件式(15)の $\rho$ に関する解の数は，付録に示すよ うに式(16)の值より判別することができる.

$$
\mathrm{D}_{\rho}(\phi)=A(\phi)^{2}+B(\phi)^{2}-\left\{\tau_{\Sigma z} \sin \phi\right\}^{2}
$$

式(6)のA $(\phi), \mathrm{B}(\phi)$ を式(16) 一代入し, $s=\tan (\phi / 2),(0<s<1)$ の置換を行うことで, 式(17)を得る.

$$
\begin{gathered}
\mathrm{D}_{\rho}(s)=\left(s^{2}-\mathrm{G}_{\mathrm{a}} s-1\right)^{2}+\left\{-\left(\mathrm{G}_{\mathrm{a}}^{2}-4 \mathrm{G}_{\mathrm{b}}\right)\right\} s^{2} \\
\left\{\begin{aligned}
\mathrm{G}_{\mathrm{a}}= & -2 \mathrm{E}\left\{H\left(\omega_{\Sigma x}^{2}+\omega_{\Sigma y}^{2}\right)+\omega_{\Sigma x} \tau_{\Sigma y}-\omega_{\Sigma y} \tau_{\Sigma x}\right\} \\
& /\left\{\left(\mathrm{H} \omega_{\Sigma x}+\tau_{\Sigma y}\right)^{2}+\left(\mathrm{H} \omega_{\Sigma y}-\tau_{\Sigma x}\right)^{2}\right\} \\
\mathrm{G}_{\mathrm{b}}= & \left\{E^{2}\left(\omega_{\Sigma x}^{2}+\omega_{\Sigma y}^{2}\right)-\tau_{\Sigma z}^{2}\right\} \\
/ & \left./\left(\mathrm{H} \omega_{\Sigma x}+\tau_{\Sigma y}\right)^{2}+\left(\mathrm{H} \omega_{\Sigma y}-\tau_{\Sigma x}\right)^{2}\right\}
\end{aligned}\right.
\end{gathered}
$$

なお, $s$ とにには, 式(18)に示す関係がある.

$$
\phi=\tan ^{-1} \frac{\sin \phi}{\cos \phi}=\tan ^{-1} \frac{2 s}{1-s^{2}}
$$

ある $\phi$ の具断面上での工具探引点の数は, $s=\tan (\phi / 2)$ を代入 した式(17)の值より判別できる. $\mathrm{D}_{\rho}(s)=0$ のとき工具㛿引点は $1 つ, \mathrm{D}_{\rho}(s)>0$ のとき工具掃引点は 2 つ存在し, $D_{\rho}(s)<0$ のと き工具掃引点は存在しない. 式(17)は, 第 1 項 $\left(p^{2}-\mathrm{G}_{\mathrm{a}} s-1\right)^{2}$ の 值が 0 以上であるため, 第 2 項の係数を $\mathrm{G}_{12}=-\left(\mathrm{G}_{\mathrm{a}}^{2}-4 \mathrm{G}_{\mathrm{b}}\right)$ とす るとき, $\mathrm{G}_{12}>0, \mathrm{G}_{12}=0, \mathrm{G}_{12}<0$ の場合で值が異なる.よって, 図 8 に示すように 3 つの場合に分け, 工具掃引タイプの分類を 行う. なお, 3.2 .にて $\tau_{\Sigma \mathrm{z}} \neq 0$ となる場合, $\mathrm{G}_{12}<0$ となる.

はじめに, $\mathrm{G}_{12}>0$ であるとき, $\phi_{\text {begin }} \leq \phi \leq \phi_{\text {end }}$ ではD $D_{\rho}(s)>$ 0 のため, 各工具断面上には工具掃引点が 2 つ存在する. よって, 
それらの工具掃引点を結んだ 2 本の曲線が工具掃引曲線となる.

次に, $\mathrm{G}_{12}=0$ であるとき, 式(17)における第 1 項 $s^{2}-\mathrm{G}_{\mathrm{a}} s$ $1=0$ の解 $S_{\text {one }}\left(s_{\text {one }}>0\right)$ では $D_{\rho}\left(s_{\text {one }}\right)=0$ となり, 式(18) $S_{\text {one }}$ を代入し得られる $\phi_{\text {one }}$ の工具断面には工具掃引点が 1 つ存在す る. また, $s \neq s_{\text {one }}$ では $\mathrm{D}_{\rho}(s)>0$ のため, 工具断面には工具掃引 点が 2 つ存在する. これより, $\phi_{\text {begin }}, \phi_{\text {end }}$ と $\phi_{\text {one }}$ の大小関係で, 図 9 に示す 4 つ具掃引タイプのいずれかとなる. i) $\phi_{\text {one }}<$ $\phi_{\text {begin }}$ または $\phi_{\text {end }}<\phi_{\text {one }}$ であるとき, $\phi_{\text {begin }} \leq \phi \leq \phi_{\text {end }}$ のすべ ての範囲で $\mathrm{D}_{\rho}(s)>0$ となる. よって, 図 9 (a)に示すように, 各 工具断面上には工具掃引点が 2 つ存在し，それらを結ぶ 2 本の 曲線が工具掃引曲線となる. ii) $\phi_{\text {begin }}<\phi_{\text {one }}<\phi_{\text {end }}$ であると き, $\phi_{\text {begin }} \leq \phi<\phi_{\text {one }}, \phi_{\text {one }}<\phi \leq \phi_{\text {end }}$ の範囲ではD $\rho(s)>0$ と なり, 工具断面上に 2 点の工具探引点が存在する. また, $\phi=$ $\phi_{\text {one }}$ ではD $\rho\left(s_{\text {one }}\right)=0$ となり, 工具断面上に 1 点の工具掃引点 が存在する. これより, 図 9 (b)に示すように, $\phi_{\text {one }}$ の位置で交 差する 2 本の曲線が工具掃引線となる. iii) $\phi_{\text {one }}=\phi_{\text {end }}$ である とき, $\phi_{\text {begin }} \leq \phi<\phi_{\text {end }}$ では $D_{\rho}(s)>0$ となり工具断面上に 2 点 の工具掃引点が存在する. また, $\phi=\phi_{\text {one }}$ では $\mathrm{D}_{\rho}\left(s_{\text {one }}\right)=0$ とな り工具断面上に 1 点の工具掃引点が存在する. これより, 図 9 (c)に示すように, 下に凸の曲線が工具掃引線となる. iv) $\phi_{\text {one }}=$ $\phi_{\text {begin }}$ であるとき, $\phi_{\text {begin }}<\phi \leq \phi_{\text {end }}$ では $D_{\rho}(s)>0$ となり工具 断面上に 2 点の工具揥引点が存在し, $\phi=\phi_{\text {begin }}$ では $\mathrm{D}_{\rho}\left(s_{\text {one }}\right)=$ 0 となり工具断面上に 1 点の工具掃引点が存在する. これより, 図 9 (d)に示すように，上に凸の曲線が工具掃引線となる.

最後に, $\mathrm{G}_{12}<0$ であるとき, 式(17)を 2 次式 $D_{1}(s), D_{2}(s)$ の積 である式(19)へ変形し，工具掃引タイプを分類する.

$$
\begin{aligned}
\mathrm{D}_{\rho}(s) & =\mathrm{D}_{1}(s) \cdot \mathrm{D}_{2}(s) \\
& =\left\{\left(s^{2}-\mathrm{G}_{\mathrm{a}} s-1\right)+\sqrt{\mathrm{G}_{\mathrm{a}}^{2}-4 \mathrm{G}_{\mathrm{b}}} s\right\} \\
& \cdot\left\{\left(s^{2}-\mathrm{G}_{\mathrm{a}} s-1\right)-\sqrt{\mathrm{G}_{\mathrm{a}}^{2}-4 \mathrm{G}_{\mathrm{b}}} s\right\}
\end{aligned}
$$

なお， $\mathrm{D}_{1}(s), \mathrm{D}_{2}(s)$ は下に凸であり，式(19)より， $0<s(0<\phi)$ において $\mathrm{D}_{1}(s)>\mathrm{D}_{2}(s)$ である. また, どちらも $s=0$ で值がー1 となるため, $D_{1}(s)=0, D_{2}(s)=0$ の 2 つの解は $s>0$ と $s<0$ の 範囲に 1 つずつ存在する. ここで, $s>0$ における $\mathrm{D}_{1}(s)=0$ の解 を $s_{\text {ans1 }}, \mathrm{D}_{2}(s)=0$ の解を $s_{\text {ans2 }}$ とする. また, $s_{\text {ans1 }}, s_{\text {ans2 }}$ を式(18) へ代入したときの值を, $\phi_{\text {ans } 1}, \phi_{\text {ans2 }}$ とする. $\phi, s, \mathrm{D}_{1}(s), \mathrm{D}_{2}(s)$, $\mathrm{D}_{\rho}(s)$ と工具掃引点の関係を表 1 に示寸. $\mathrm{D}_{1}(s)$ は $s=s_{\text {ans } 1}$ を境 に, $\mathrm{D}_{2}(s)$ は $s=s_{\text {ans2 }}$ を境に, 值が負から正となる.これらより， $0 \leq \mathrm{s}<s_{\text {ans1 }} に \tau D_{\rho}(s)>0, s=s_{\text {ans1 }} に \tau D_{\rho}(s)=0, \quad s_{\text {ans1 }}<$ $s<s_{\text {ans2 }}$ にてD $(s)<0, s=s_{\text {ans2 }}$ に $\mathrm{D}_{\rho}(s)=0, s>s_{\text {ans2 }}$ にて $\mathrm{D}_{\rho}(s)>0$ となる. よって, 工具断面における工具掃引点の数は, $\mathrm{s}$ の増加に伴い, $2,1,0,1,2$ の順に変化する. 以上より, $\phi_{\text {begin }}, \phi_{\text {end }}, \phi_{\text {ans1 }}, \phi_{\text {ans2 }}$ の大小関係で, 図 10 に示寸工具㧸引 タイプのいずれかとなる. i) $\phi_{\text {end }}<\phi_{\text {ans1 }}$ または $\phi_{\text {begin }}>\phi_{\text {ans2 }}$ であるとき, $\phi_{\text {begin }} \leq \phi \leq \phi_{\text {end }}$ では $\mathrm{D}_{\rho}(s)>0$ となり, 全ての工 具断面上に 2 点の工具㛿引点が存在する. これより, 図 10 (a), (b)に示すように, それらの工具掃引点をつなぐ 2 本の曲線が工 具掃引線となる. ii) $\phi_{\text {begin }} \leq \phi_{\text {ans1 }}$ かつ $\phi_{\text {ans2 }} \leq \phi_{\text {end }}$ であるとき, $\phi_{\text {begin }}<\phi<\phi_{\text {ans1 } 1}, \phi_{\text {ans2 }}<\phi<\phi_{\text {end }}$ では $\mathrm{D}_{\rho}(s)>0$ となるた め工具断面上に 2 点の工具掃引点が存在し, $\phi=\phi_{\text {ans1 }}, \phi_{\text {ans2 }}$ で は $\mathrm{D}_{\rho}(s)=0$ となるため工具断面上に 1 点の工具掃引点が存在す る. また, $\phi_{\text {ans1 }}<\phi<\phi_{\text {ans2 }}$ では $\mathrm{D}_{\rho}(s)<0$ となるため掃引され ない. これより, 図 10 (c)に示すように, 上下に凸の 2 本の曲線 が工具掃引線となる. iii) $\phi_{\text {begin }} \leq \phi_{\text {ans1 }}$ かつ $\phi_{\text {end }}<\phi_{\text {ans2 }}$ であ

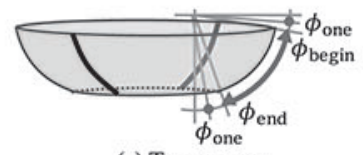

(a) Two curves

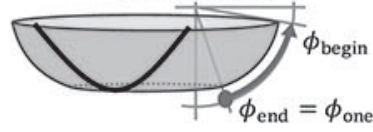

(c) Concave downward curve

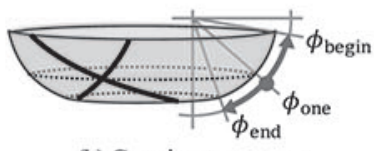

(b) Crossing two curves

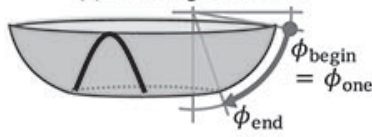

(d) Concave upward curve - : Tool swept profile curve

Fig. 9 Tool swept types of torus in $\mathrm{G}_{12}=0$ of Section 3.3

Table 1 Number of tool swept points in $0<\phi<\pi / 2$

\begin{tabular}{c|c|c|c|c|c|c}
\hline$\phi$ & 0 & $\rightarrow$ & $\phi_{\text {ans1 }}$ & $\rightarrow$ & $\phi_{\text {ans2 }}$ & $\rightarrow$ \\
\hline$s$ & 0 & $\rightarrow$ & $s_{\text {ans } 1}$ & $\rightarrow$ & $s_{\text {ans2 }}$ & $\rightarrow$ \\
\hline $\mathrm{D}_{1}(s)$ & $=-1$ & $<0$ & $=0$ & \multicolumn{4}{|c}{$>0$} \\
\hline $\mathrm{D}_{2}(s)$ & $=-1$ & $<0$ & $<0$ & $<0$ & $=0$ & $>0$ \\
\hline $\mathrm{D}_{0}(s)$ & $=1$ & $>0$ & $=0$ & $<0$ & $=0$ & $>0$ \\
\hline $\begin{array}{c}\text { Number of } \\
\text { tool swept points }\end{array}$ & 2 & 2 & 1 & 0 & 1 & 2 \\
\hline
\end{tabular}

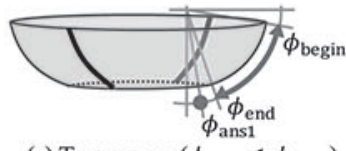

(a) Two curves $\left(\phi_{\text {end }}<\phi_{\text {ans1 }}\right)$

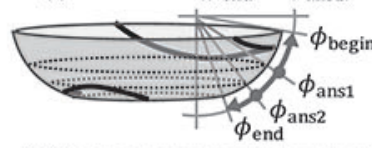

(c) Concave upward and downward curves

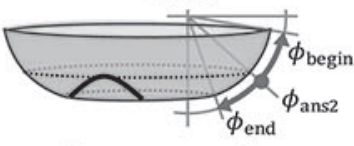

(e) concave upward curve
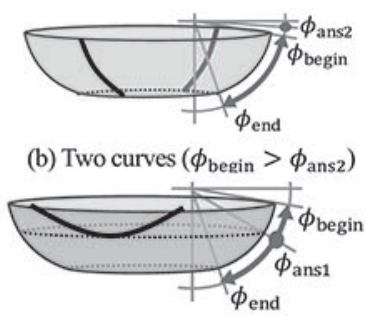

(d) Concave downward curve

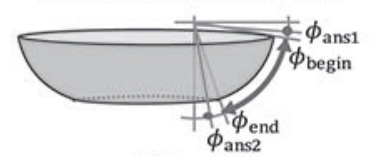

(f) Not swept (b) Two curves ( $\left.\phi_{\text {begin }}>\phi_{\text {ans2 }}\right)$

$$
\text { - : Tool swept profile curve }
$$

Fig. 10 Tool swept types of torus in $\mathrm{G}_{12}<0$ of Section 3.4

るとき, $\phi_{\text {begin }} \leq \phi<\phi_{\text {ans } 1}$ では $D_{\rho}(s)>0$ となるため工具断面 上に 2 点の工具掃引点が存在し, $\phi=\phi_{\text {ans1 }}$ では $D_{\rho}\left(s_{\text {ans } 1}\right)=0$ と なるため工具断面上に 1 点の工具掃引点が存在する. また, $\phi_{\text {ans1 }}<\phi \leq \phi_{\text {end }}{ } \mathrm{D}_{\rho}(s)<0$ となり掃引されない. これより， 図 10 (d)に示すように，下に凸の曲線が工具掃引線となる. iv) $\phi_{\text {ans1 }}<\phi_{\text {begin }}$ かつ $\phi_{\text {ans2 }} \leq \phi_{\text {end }}$ であるとき, $\phi_{\text {ans } 2}<\phi \leq \phi_{\text {end }}$ では $\mathrm{D}_{\rho}(s)>0$ となるため工具断面上に 2 点の工具㛿引点が存在 し, $\phi=\phi_{\text {ans2 }}$ では $D_{\rho}\left(s_{\text {ans2 }}\right)=0$ となるため工具断面上に 1 点の 工具掃引点が存在する. また, $\phi_{\text {begin }} \leq \phi<\phi_{\text {ans } 2}$ はD $\rho(s)<0$ と なり掃引されない. これより, 図 10 (e)に示すように, 上に凸の 曲線が工具掃引線となる. v) $\phi_{\text {ans1 }}<\phi_{\text {begin }}$ かつ $\phi_{\text {end }}<\phi_{\text {ans2 }}$ で あるとき， $\phi_{\text {begin }} \leq \phi \leq \phi_{\text {end }}$ ではD $D_{\rho}(s)<0$ となり，図 $10(\mathrm{f})$ に 示すように, 工具断面上に工具掃引点は無く, 掃引されない.

$$
\text { 4. ケーススタディ }
$$

ケーススタディにより，工具運動を表す平行速度ベクトル $\boldsymbol{\tau}_{\Sigma}$ と角速度ベクトル $\omega_{\Sigma}$ から, 提案手法による工具掃引タイプ判別, 工具掃引領域導出を行い, 工具運動に対し工具掃引領域が正し く得られることをグラフィクス表示により確認することで, 提 案手法の有効性を示す. ケーススタディでは, 図 3 に示寸母線 で表現されるラジアスエンドミル $\left(\mathrm{R}=10 \mathrm{~mm}, \mathrm{R}_{\mathrm{tc}}=5 \mathrm{~mm}\right.$, $\left.\phi_{\text {begin }}=1.25 \mathrm{deg}, \phi_{\text {end }}=88.75 \mathrm{deg}, \mathrm{L}=40 \mathrm{~mm}\right)$ のコーナー ラジアスを対象に, CAYXZ 型の 5 軸工作機械にて表 2 に示す 2 つの指令を実施する際の工具掃引タイプの判別と工具掃引領域 
の導出を行う. なお, 判別・導出は, 分割した工具パスの䧿散的 な各位置にて行う. また, 指令 1 では, 形状剳成理論 1における 定義に基づき，Y軸方向の並進駆動軸，A軸回りの回転駆動軸， Y, A駆動軸間, に生じる幾何学的誤差を考虑した. 誤差量は工具 運動計算の簡単化のため表 3 に示すように固定值とする.なお, $\alpha, \beta, \gamma$ は駆動軸におけるX,Y,Z軸回りの角度誤差量, $\delta_{x}, \delta_{y}, \delta_{z}$ は駆 動軸におけるX,Y,Z軸方向への位置決め誤差量を表す. 指令 1 に よるコーナーラジアスの運動を図 11 (a), (b)に, 指令 2 によるコ 一ナーラジアスの運動を図 12 (a), (b)に示す．また，指令 1 にお ける工具掃引領域を図 11 (c), (d)に, 指令 2 における工具掃引領 域を図 12 (c), (d)に示す. なお, 図 11(a), (c), 図 12 (a), (c)はコー ナーラジアス側面から見た図であり, 図 11(b), (d), 図 12 (b), (d) は底面から見た図である. 指令 1 では, 下に凸の曲線が工具掃 引領域として導出される. 指令 2 では, 円と 2 本の曲線が工具 掃引領域として導出される. 2 つケーススタディについて, エ 具動作と導出される工具掃引領域を比較すると, 工具運動に対 し正しく工具㛿引領域が導出できていることがわかる. なお, 提 案手法は誤差量が動的に変化する場合でも, 平行速度ベクトル $\boldsymbol{\tau}_{\Sigma}$ と角速度ベクトル $\omega_{\Sigma}$ が求まるので, 工具掃引タイプ判別と工 具掃引領域導出が可能である.

\section{5. 結言}

本研究では, 多軸加工における一般的な工具形状を対象に, 工具掃引条件の成立条件を解析することで, 工具掃引領域の形 状と, それに対する工具運動を工具掃引タイプとして分類して いる. 本論文では, ラジアスエンドミルのコーナーラジアス部分 を表すトーラス形状に対し, 工具掃引条件式より工具掃引タイ プの判別式を求め, 8 つ具揥引タイプがあることを明らかに した. これにより, 任意の工具運動における工具掃引領域の形状 を判別可能となる. またケーススタディにて, 幾何学的誤差を含 む場合と含まない場合の多軸加工を対象に, ラジアスエンドミ ルのコーナーラジアス側面の工具掃引タイプの判定と工具掃引 領域の導出を行った. また, 工具運動と工具掃引領域を比較する ことで, 正しく工具掃引領域が導出されていることを確認した. 今後の課題として, 工具表面の法線ベクトルが不連続な領域に 対する工具掃引タイプの分類や, 各工具掃引タイプに対する工 具掃引体導出手法の提案が挙げられる.

\section{付 録}

工具掃引条件式(A1)に対し, $q=\tan \{(\rho+\mu(\phi)) / 2\}$ の置換を 行うと, 変数 $q$ に関する方程式(A2)を得る.

$$
\begin{gathered}
\sqrt{\mathrm{A}(\phi)^{2}+\mathrm{B}(\phi)^{2}} \sin (\rho+\mu(\phi))+\mathrm{C}(\phi)=0 \\
\mu(\phi)=\tan ^{-1} \frac{\sin \mu(\phi)}{\cos \mu(\phi)}=\tan ^{-1} \frac{\mathrm{A}(\phi)}{\mathrm{B}(\phi)} \\
\frac{\mathrm{C}(\phi) q^{2}+2 \sqrt{\mathrm{A}(\phi)^{2}+\mathrm{B}(\phi)^{2}} q+\mathrm{C}(\phi)}{1+q^{2}}=0
\end{gathered}
$$

式(A2)について, $q \in \mathrm{R} よ り$, 式(A2)の解は, 式(A2)の分子部分 から得られる. また, $q \in \mathrm{R}, 0 \leq \rho<2 \pi よ り, q か ゙$ 定まるとき, $\rho$ は一意に定まる. 以上より, $\mathrm{C}(\phi) \neq 0$ \%とき, 工具掃引条件式 (A1)の $\rho$ に関する解の数は, 式(A2)の分子部分である $q$ に関する 2 次方程式の判別式(A3)の值より判別することができる.

$$
\mathrm{D}_{\rho}(\phi)=\mathrm{A}(\phi)^{2}+\mathrm{B}(\phi)^{2}-\mathrm{C}(\phi)^{2}
$$

なお, $\mathrm{D}_{\rho}(\phi)=0$ のとき $\rho$ の解は 1 つ存在し, $D_{\rho}(\phi)>0$ のとき $\rho$ の解は 2 つ存在し, $\mathrm{D}_{\rho}(\phi)<0$ のとき $\rho$ の解は存在しない.
Table 2 Operations for case studies

\begin{tabular}{c|c|c|c|c|c|c}
\hline \multicolumn{2}{c|}{ Operation } & X mm & Y mm & Z mm & A deg & C deg \\
\hline \multirow{2}{*}{1} & Start & -5 & -5 & 30 & 10 & -3 \\
\cline { 2 - 7 } & End & 5 & -20 & 33 & -10 & 3 \\
\hline \multirow{2}{*}{2} & Start & 0 & 0 & 40 & -25 & 45 \\
\cline { 2 - 7 } & End & 0 & 0 & 40 & 25 & 45 \\
\hline \multicolumn{7}{c}{ Table 3 Error parameters for case studies } \\
\hline Axis & $\alpha$ deg & $\beta$ deg & $\gamma$ deg & $\delta_{\mathrm{x}} \mathrm{mm}$ & $\delta_{\mathrm{y}} \mathrm{mm}$ & $\delta_{\mathrm{z}} \mathrm{mm}$ \\
\hline Y & 0.01 & 0.07 & 0.09 & 0.04 & 0.08 & 0.03 \\
\hline A & 0.05 & 0.07 & 0.06 & - & - & - \\
\hline Y - A & 0.07 & 0.07 & 0.06 & 0.03 & 0.02 & 0.02 \\
\hline
\end{tabular}

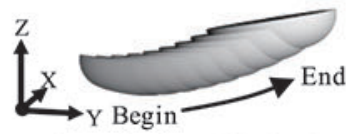

(a) Tool motion (side view)

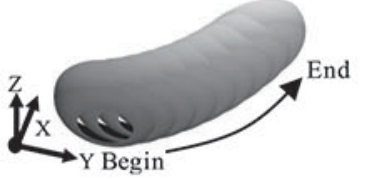

(b) Tool motion (bottom view)

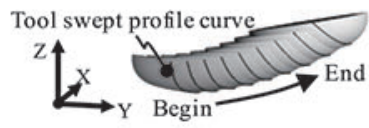

(c) Tool swept profile curves (side view) Tool swept profile curve

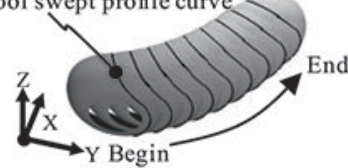

(d) Tool swept profile curves (bottom view)
Fig. 11 Results of deriving tool swept profile curves of Operation 1

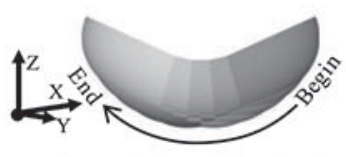

(a) Tool motion (side view)

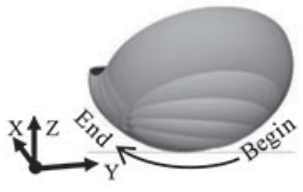

(b) Tool motion (bottom view)

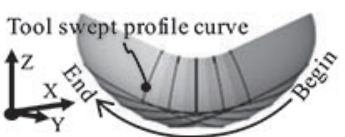

(c) Tool swept profile curves (side view)

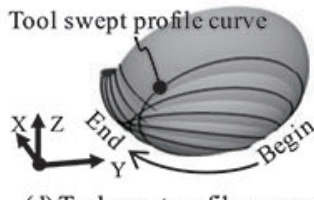

(d) Tool swept profile curves (bottom view)
Fig. 12 Results of deriving tool swept profile curves of Operation 2

\section{考 文 献}

1) 稻崎一郎, 岸浪建史, 坂本重彦, 杉村延広, 竹内芳美, 田中文基: 工 作機械の形状剳成理論 一その基礎と応用一，莨堅堂，(1997).

2) 成田浩久, 白濑敬一, 若松栄史, 荒井栄司: ヴァーチャルマシニング シミュレータを用いた NC プログラムの評価と修正, 日本機械学会 踚文集(C 編), 66, 648 (2000) 401.

3) Mohsen S., Behrooz A., Mohsen H.: Dimensional and geometrical errors of three-axis $\mathrm{CNC}$ milling machines in a virtual machining system, Computeraided design, 45 (2016) 1306.

4) Wang W. P. and Wang K. K.: Geometric modeling for swept volume of moving solids, IEEE Computer Graphics and Applications, 6, 12 (1986) 8.

5) D. Blackmore, M. C. Leu and L. P. Wang: The sweep-envelope differential equation algorithm and its application to $\mathrm{NC}$ machining verification, Computer Aided-Design, 29 (1997) 629.

6) C. -J. Chiou, Y.-S. Lee: Swept surface determination for five-axis numerical control machining, International Journal of Machine Tools \& Manufacture, 42 (2002) 1497.

7) LiMin Z., Gang Z., Han D.: Formulating the swept envelope of rotary cutter undergoing general spatial motion for multi-axis $\mathrm{NC}$ machining, International Journal of Machine Tools \& Manufacture, 49 (2009) 199.

8) Seok W. L., Andreas N.: Complete swept volume generation, Part I: Swept volume of piecewise $\mathrm{Cl}$-continuous cutter at five-axis milling via Gauss map Computer-Aided Design, 43 (2011) 427.

9) Bharat A., Jinesh M., Milind S.: Local and global analysis of parametric solid sweeps, Computer Aided Design, 31 (2014) 294.

10) Wataru ARAI, Fumiki TANAKA and Masahiko ONOSATO: Tool swept types analysis based on tangency condition for generating tool swept volumes of generalized tool, Proceedings of ISFA 2016 (2016).

11) 荒井 航, 田中文基, 小野里雅彦: 誤差を伴う多軸加工における工 具揥引曲線を用いた工具掃引体導出手法の提案(第 4 報) ラジアスエ ンドミル工具底面の工具㛿引状態分類, 精密工学会秋季学術满演会 論文集 (2016) 685 . 